\title{
Método para Avaliar O Fator de Qualidade da Blindagem de Cabos Coaxiais
}

Kenedy Marconi Geraldo dos Santos, José Osvaldo Saldanha Paulino, Marcelo Blender Perotoni, Arnaud Colin, Mario Fernando Barbosa e Caio Luminatti Andrade

IFBA-VC - Instituto Federal da Bahia

UFMG - Universidade Federal de Minas Gerais

UFABC - Universidade Federal do ABC

FIASA - Fiat Automóveis - S/A

USP- Universidade de São Paulo

SENAI - Cimatec

E-mails: kenedymarconi@gmail.com; josvaldo@cpdee.ufmg.br; marcelo.perotoni@ufabc.edu.br; arnaud.colin@fiat.com.br; barbosa@ipt.br; caio.luminatti@fieb.org.br

\section{RESUMO}

Uma blindagem eficiente é um item importante para garantir o funcionamento adequado dos equipamentos eletroeletrônicos. Dentro deste contexto, este trabalho apresenta uma metodologia simplificada para a medição do fator de qualidade da blindagem de cabos coaxiais, com a qual é possível determinar o fator de qualidade da blindagem de qualquer cabo coaxial. Foi realizada também uma modelagem computacional com uso do software CST-MWS®Microwave Studio.

\section{INTRODUÇÃO}

O uso de sistemas eletroeletrônicos em automóveis vem assumindo um papel indispensável para o aumento do conforto, segurança e diminuição das emissões de $\mathrm{CO}_{2}$. A eletroeletrônica embarcada está cada vez mais presente no veículo, sem contar os sistemas de telecomunicações que operam em frequências diversas e com elevados níveis de campo eletromagnético. Apesar dos grandes benefícios e facilidades destes sistemas, eles podem introduzir distúrbios eletromagnéticos nos diversos ambientes em que operam. Neste contexto, compatibilidade eletromagnética - EMC é a capacidade de um equipamento eletroeletrônico funcionar corretamente em um determinado ambiente eletromagnético, sem perturbar os equipamentos adjacentes ou sem ser perturbado por outros equipamentos ou por si próprio [1]. Normalmente, um problema de compatibilidade eletromagnética pode ser dividido basicamente em três partes, conforme ilustra a Figura 1:

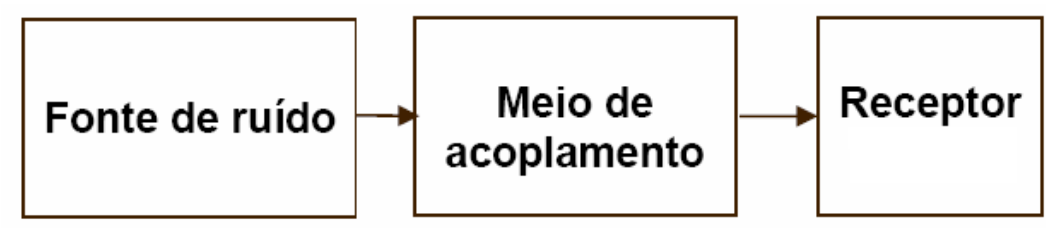

Fig.1 - Diagrama em blocos referente a geração, transmissão e a vítima da interferência 
Fonte de ruído - Estas fontes podem ser transmissores, motores, computadores, raios ou qualquer equipamento capaz de gerar energia eletromagnética;

Meio de acoplamento - $\mathrm{O}$ acoplamento pode ser através de condutores, meio indutivo, capacitivo etc;

Receptor - A vítima poderá ser pessoas, computadores, centrais eletrônicas etc.

\section{1- DESCRIÇÃO DO PROBLEMA}

Para se minimizar um problema de EMC pode-se atuar na fonte, no receptor ou no meio de acoplamento. No entanto, para este estudo, o meio de acoplamento é o elemento que será investigado no sentido de mitigar as interferências eletromagnéticas irradiadas ou induzidas. Uma das técnicas utilizadas para minimizar esta interferência é a blindagem de determinados condutores. Sabe-se que a central de injeção é um sistema de alta relevância para o funcionamento do veículo, portanto condutores responsáveis pela transmissão de sinais provenientes dos sensores, como por exemplo, o sensor de giro, devem possuir uma blindagem a fim de garantir a imunidade a ruídos eletromagnéticos. Um cabo coaxial com baixo desempenho de blindagem pode apresentar alguns problemas quando utilizado em um ambiente poluído na ótica eletromagnética. No caso veicular, se for instalado próximo a uma bobina de alta tensão ou motores elétricos, este condutor fica susceptível a ruídos provenientes destes componentes. Estes distúrbios podem gerar variações na frequência e na amplitude do sinal presente neste condutor, o que pode vir a causar erros no funcionamento das centrais eletrônicas a ele conectadas.

\section{1- Fator de blindagem}

O fator de blindagem efetiva (SE - Shilding Effectiveness) é definido como a atenuação em decibéis entre o campo elétrico ou magnético sem e com a blindagem, ou a relação, em decibéis, entre a tensão induzida com e sem a blindagem conforme descreve a Equação 1 [2].

$\mathrm{SE}_{\mathrm{dB}}=20 \log \frac{\mathrm{V}(\text { sem blindagem })}{\mathrm{V}(\text { com blindagem })} \quad \mathrm{SE}_{\mathrm{dB}}=20 \log \frac{\mathrm{E}(\text { campo elétrico sem blindagem })}{\mathrm{E}(\text { campo elétrico com blindagem })}$

Com o intuito de conhecer o fator de qualidade da blindagem de um cabo coaxial, utilizou-se a metodologia descrita no item 2 .

\section{2 - METODOLOGIA}

Sabe-se que a impedância de surto de um cabo coaxial depende de sua geometria [1]. Como descreve a Equação-2.

$$
Z c=\sqrt{\frac{L}{C}}
$$

Onde:

$\mathrm{Zc}=$ Impedância de surto em $\Omega$;

$\mathrm{L}=$ Indutância do cabo em $\mu \mathrm{H} . \mathrm{m}$;

$\mathrm{C}=$ Capacitância do cabo em pF.m. 


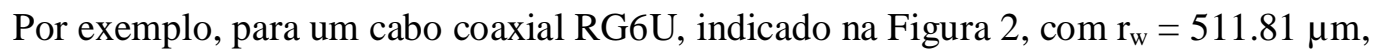
$\mathrm{r}_{s}=2.286 \mathrm{~mm} \mathrm{e} \varepsilon_{\mathrm{r}}=1.45$ tem-se:

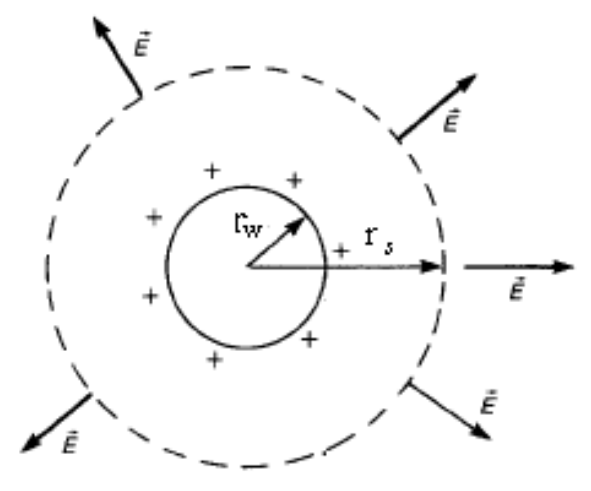

Fig.2 - Indicação dos raios internos e externos utilizados no cálculo dos parâmetros do cabo coaxial

$$
\begin{aligned}
& C=\frac{2 \pi \varepsilon}{\ln \left(\frac{r_{s}}{r_{w}}\right)}=\frac{2 \pi \varepsilon_{\mathrm{o}} \times 1.45}{\ln \left(\frac{2.286 \times 10^{-3}}{511.81 \times 10^{-6}}\right)} \Rightarrow C=53.9 \mathrm{pF} / \mathrm{m} \\
& L=\frac{\mu_{\mathrm{o}}}{2 \pi} \times \ln \left(\frac{r_{s}}{r_{w}}\right)=\frac{\mu_{\mathrm{o}}}{2 \pi} \times \ln \left(\frac{2.286 \times 10^{-3}}{511.81 \times 10^{-6}}\right) \Rightarrow L=0.3 \mu \mathrm{H} / \mathrm{m} \\
& v=\frac{v_{\mathrm{o}}}{\sqrt{\varepsilon_{\mathrm{o}}}}=\frac{3 \times 10^{8}}{\sqrt{1.45}}=2.4914 \times 10^{8} \mathrm{~m} / \mathrm{s} \Rightarrow \frac{2.4914}{3}=0.83=83 \% \text { de } v_{\mathrm{o}}
\end{aligned}
$$

Cálculo da impedância de surto:

$$
Z c=\sqrt{\frac{L}{C}}=\sqrt{\frac{0,3 \mu H / m}{53.9 p F / m}}=74,7 \cong 75 \Omega
$$

Para determinar o fator de qualidade da blindagem de um cabo coaxial, utilizou-se um arranjo específico composto por um plano metálico, um gerador de rádio frequência (RF) conectado a um amplificador de RF, um atenuador, uma carga resistiva de $50 \Omega$, uma current probe e um analisador de espectro [3]. Num primeiro instante, mediu-se, no cabo com a blindagem a tensão no final da linha de transmissão para toda faixa de freqüência de interesse, conforme configuração apresentado na Figura 3.

Este procedimento tem o intuito de definir um parâmetro de referência, isto é, frequência versus amplitude. Em seguida, esta resposta em frequência foi armazenada na memória do analisador de espectro com o nome resposta em frequência-1. 


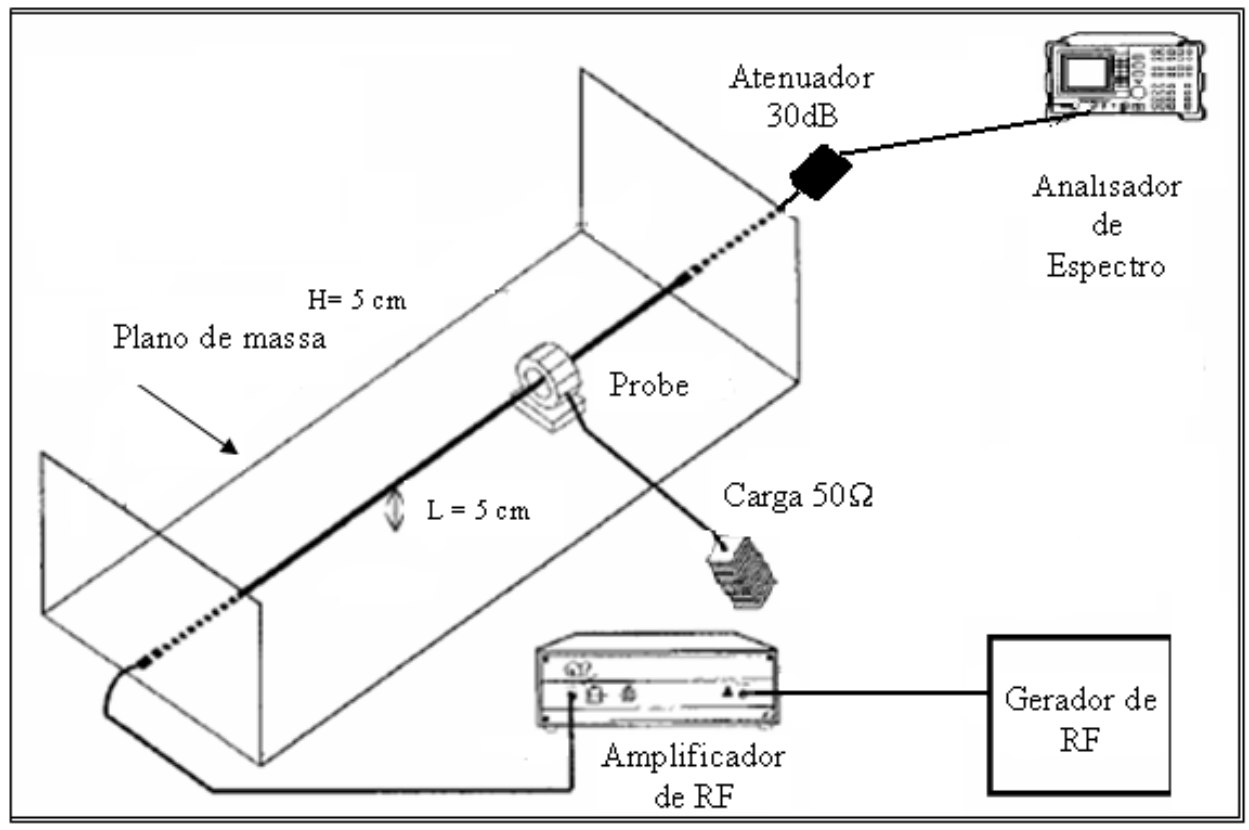

Fig.3 - Configuração utilizada para medição da resposta em frequência

Para a determinação do fator de qualidade da blindagem utilizou-se o arranjo da Figura 4, gerando-se a mesma quantidade de energia anteriormente lida pelo analisador de espectro, resposta em frequência-1, e mediu-se a energia irradiada pelo cabo com a blindagem.

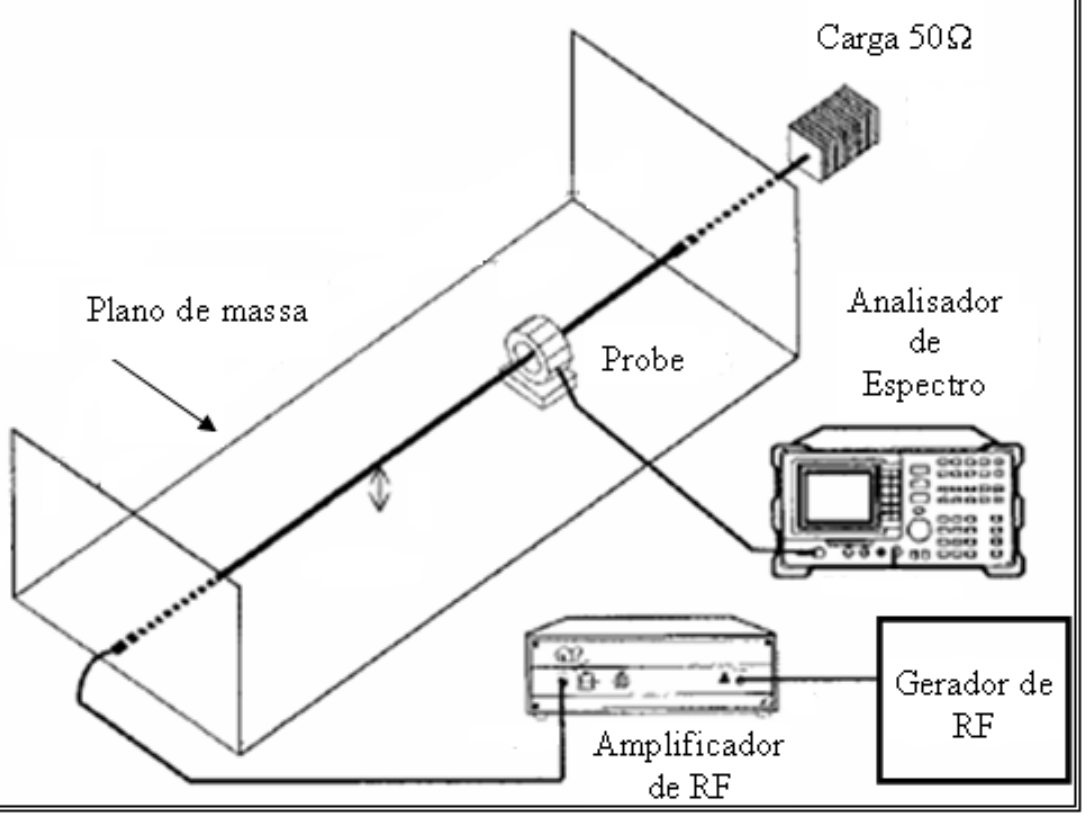

Fig.4 - Arranjo utilizado para medição do fator de blindagem do cabo coaxial 
Realizados estes testes, retirou-se a blindagem do cabo em estudo no local onde está localizada a current probe. Em seguida, utilizando-se do arranjo apresentado na Figura 3, com o cabo coaxial sem blindagem, ajustou-se a amplitude do gerador até garantir que a energia no cabo sem a blindagem fosse a mesma presente no cabo coaxial com a blindagem, medida anteriormente e memorizada no analisador de espectro (resposta em frequência-1). Novamente, usou-se o arranjo da Figura 4 e realizou-se a última medição, isto é, a medição da tensão no cabo sem a blindagem [2]. Nestas condições, obtiveram-se os níveis de tensões sem e com blindagem. A partir da Equação 1, determinou-se o fator de qualidade da blindagem deste condutor. A Figura 5 apresenta os equipamentos utilizados durante os ensaios.

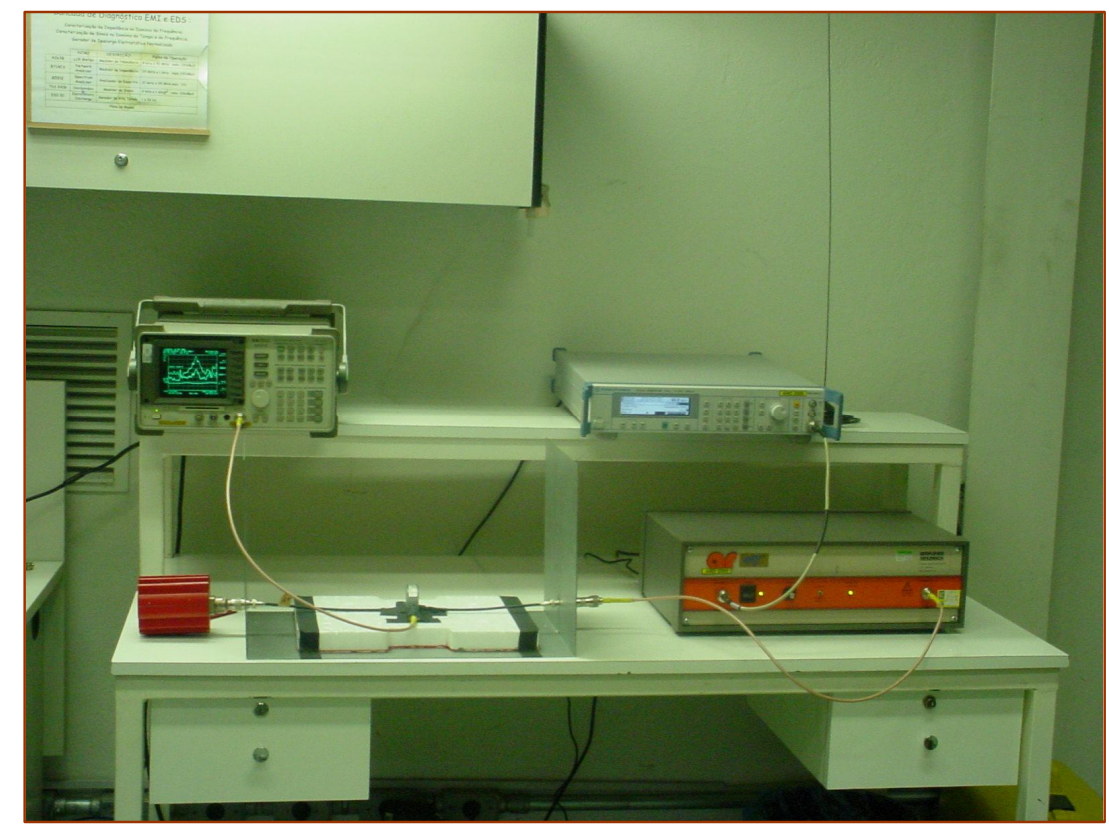

Fig.5 - Arranjo utilizado para medição da impedância do cabo coaxial

\section{3 - RESULTADOS}

A partir das medições realizadas, obtiveram-se as curvas apresentadas na Figura 6, a partir das quais pode-se verificar a diferença de amplitude entre as medições com e sem blindagem. Quanto menor a tensão proveniente do cabo com a blindagem melhor será a qualidade deste condutor na ótica da compatibilidade eletromagnética, ou seja, ele apresentará um alto nível de imunidade e um baixo nível de emissões eletromagnéticas. Observa-se também que, em altas frequências, o condutor apresenta maiores perdas devido ao efeito pelicular. 


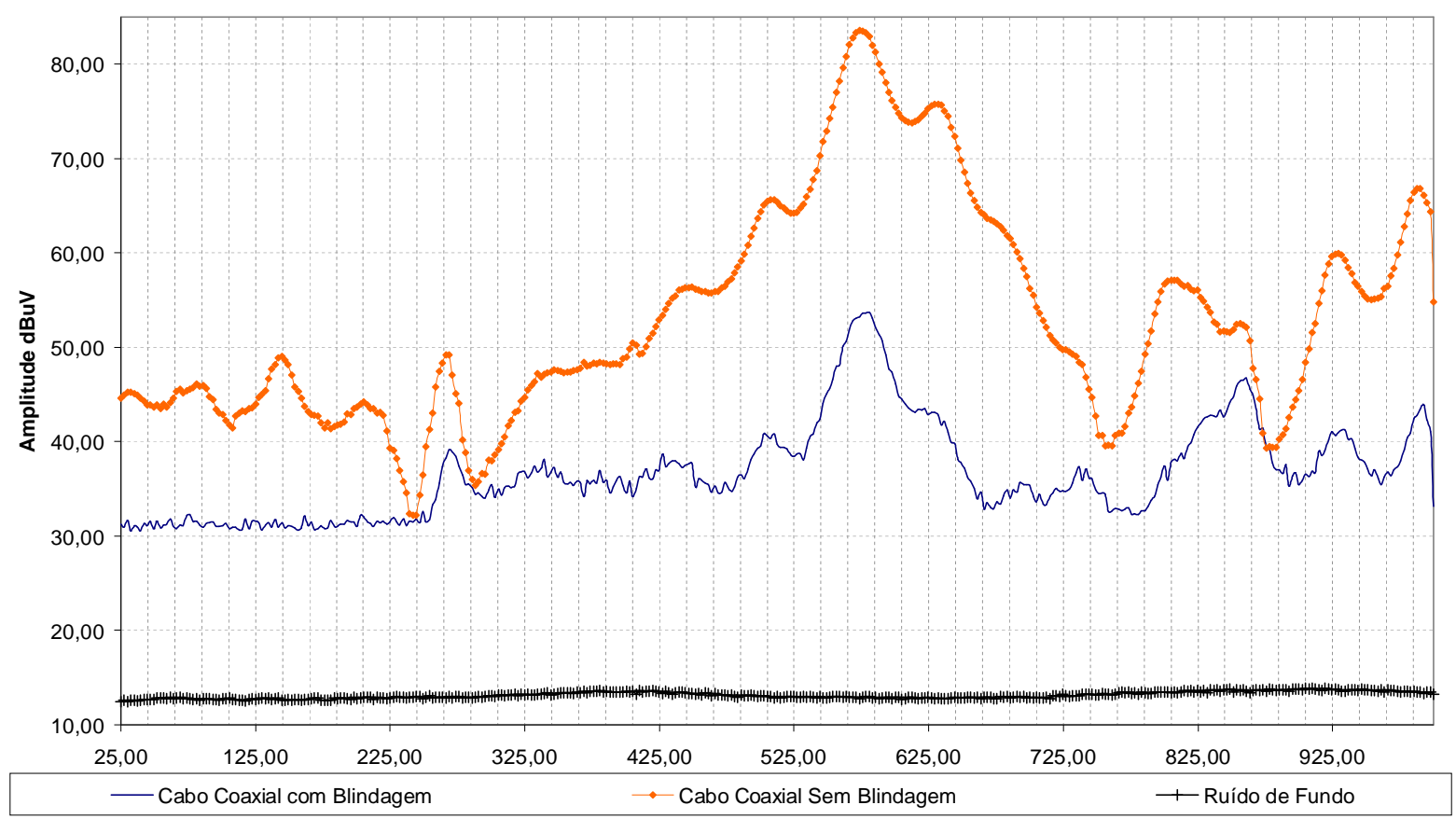

Fig.6- Resposta em frequência do cabo coaxial com blindagem versus o mesmo cabo sem blindagem

O gráfico da Figura 7 é referente ao cálculo, com a utilização da Equação 1, do fator de qualidade da blindagem. Verifica-se que o fator de qualidade da blindagem é maior nas frequências de $525 \mathrm{MHz}$ a $625 \mathrm{MHz}$. Nestas frequências o cabo coaxial sob ensaio apresentou o seu melhor desempenho.

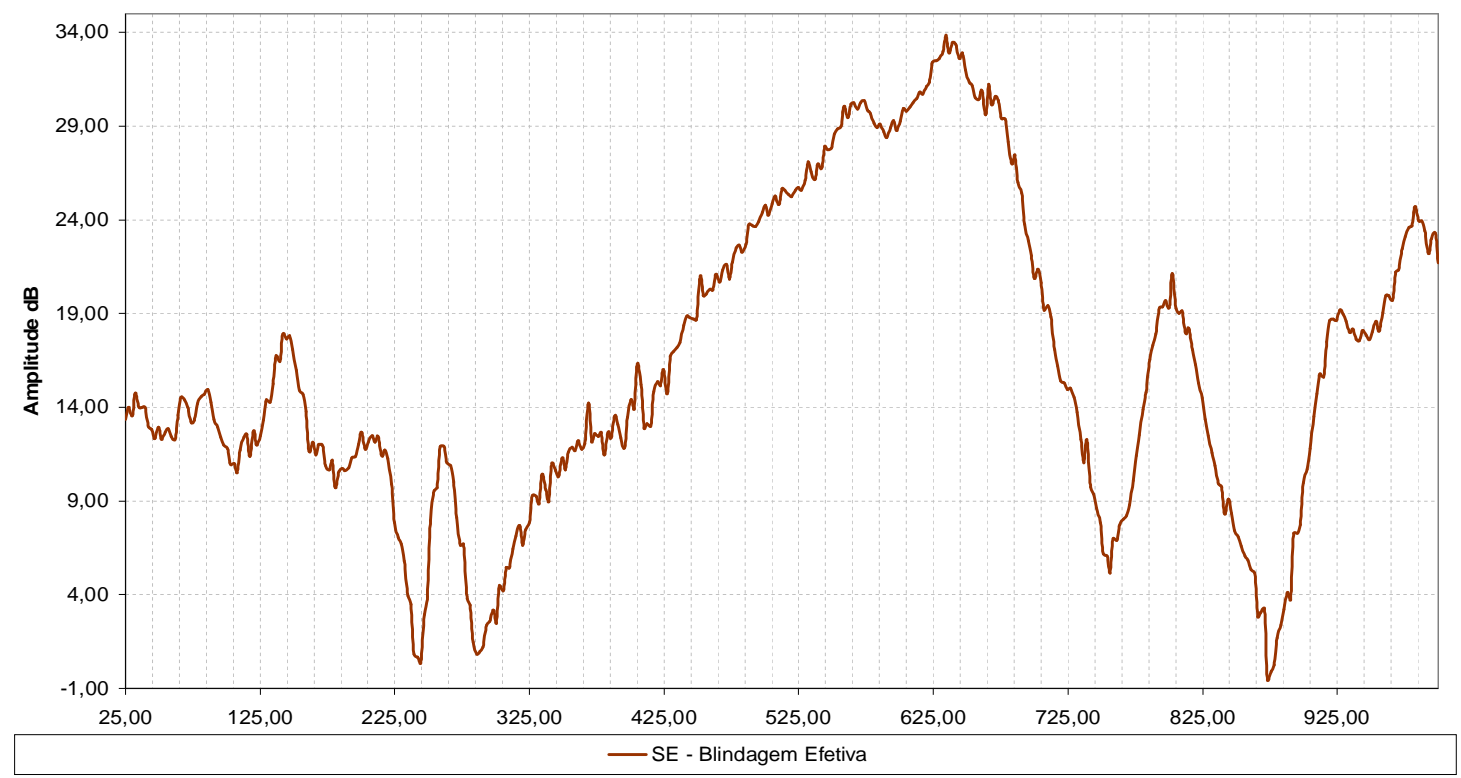

Fig.7- Gráfico referente ao cálculo do fator de qualidade da blindagem do cabo coaxial em estudo 


\section{4 - SIMULAÇÃO VIRTUAL}

Foi realizada também uma modelagem virtual do cabo coaxial, clássico, modelo RG-58 através do simulador virtual CST MWS [6]. Esta modelagem inicia-se com a escolha de um template, cujos parâmetros sejam os adequados à situação, ou seja, neste caso referente à modelagem do cabo blindado na faixa de frequência de $240 \mathrm{MHz}$ a $1 \mathrm{GHz}$. As Figuras 8 e 9 apresentam alguns detalhes do modelo utilizado. Os resultados podem ser observados nas Figuras 10 e 11. Não foi feita uma correlação, valor simulado versus o valor medido, pelo fato que no modelo computacional a medição foi realizada com um sensor de campo elétrico virtual e não uma current probe.

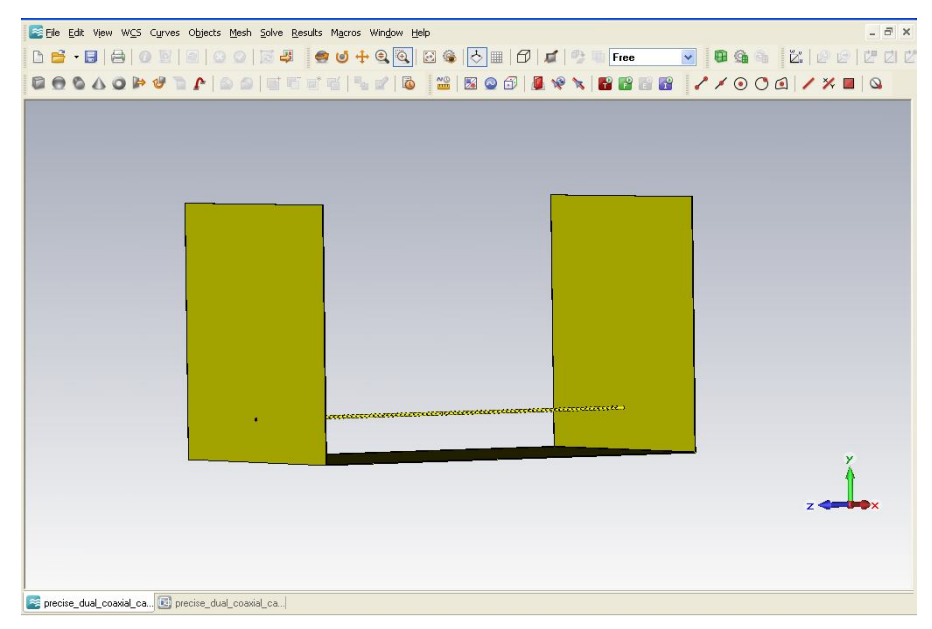

Fig. 8 - Modelagem do cabo coaxial RG-58 com blindagem

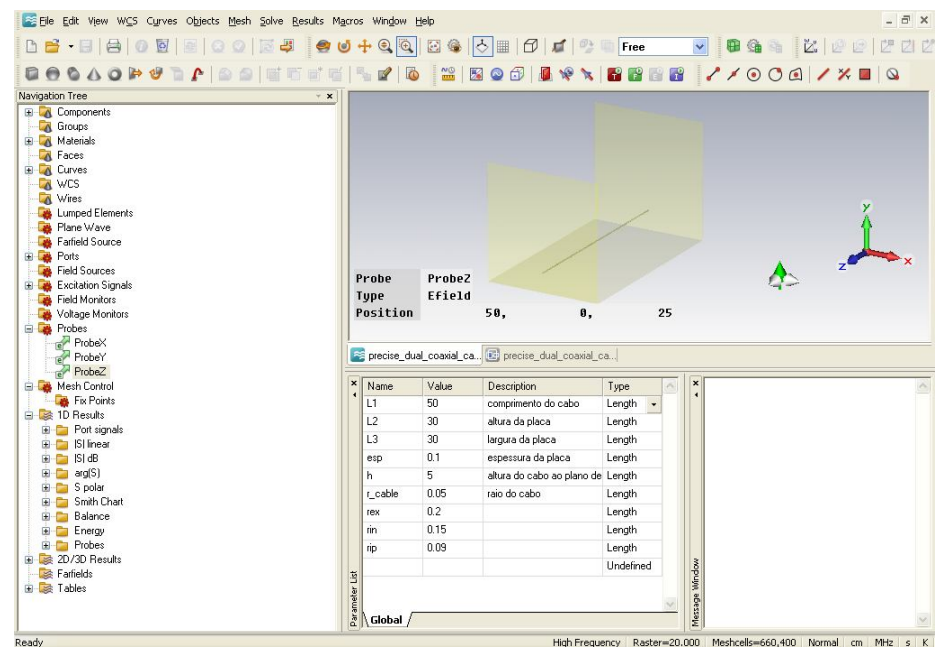

Fig. 9 - Localização do sensor de campo elétrico virtual 


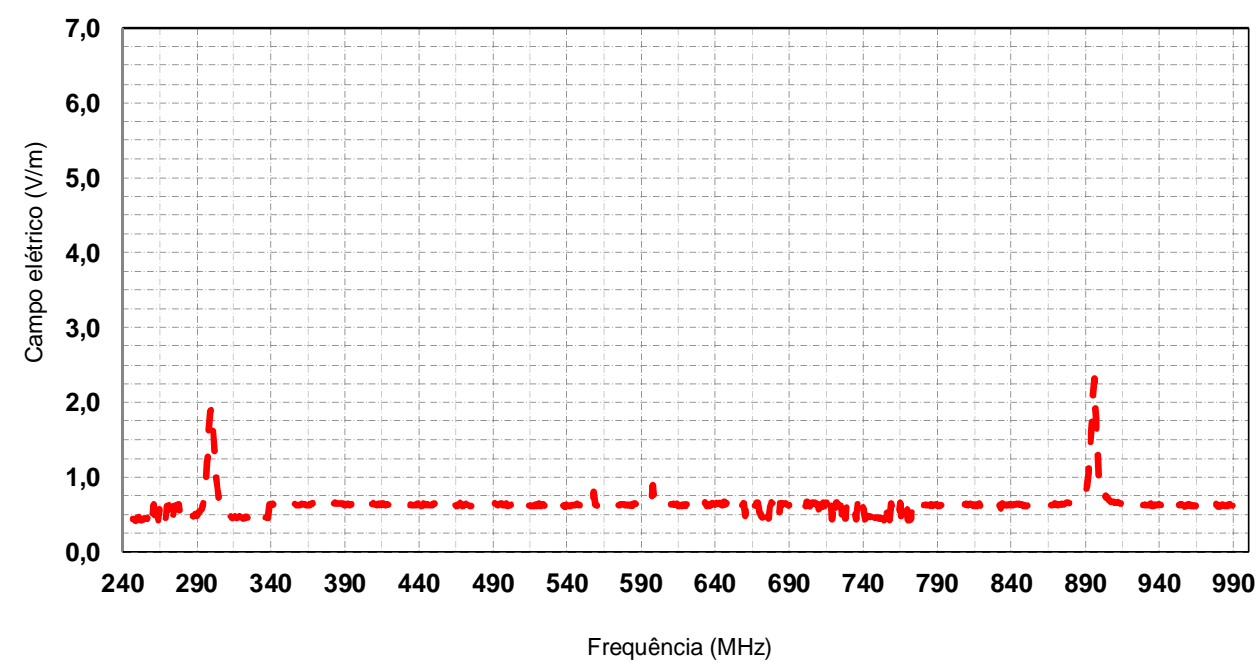

- Simulação Campo Elétrico com blindagem-RG 58 (50 W)

Fig. 10 - Valor do campo elétrico simulado sem a abertura de $10 \mathrm{~cm}$ na blindagem

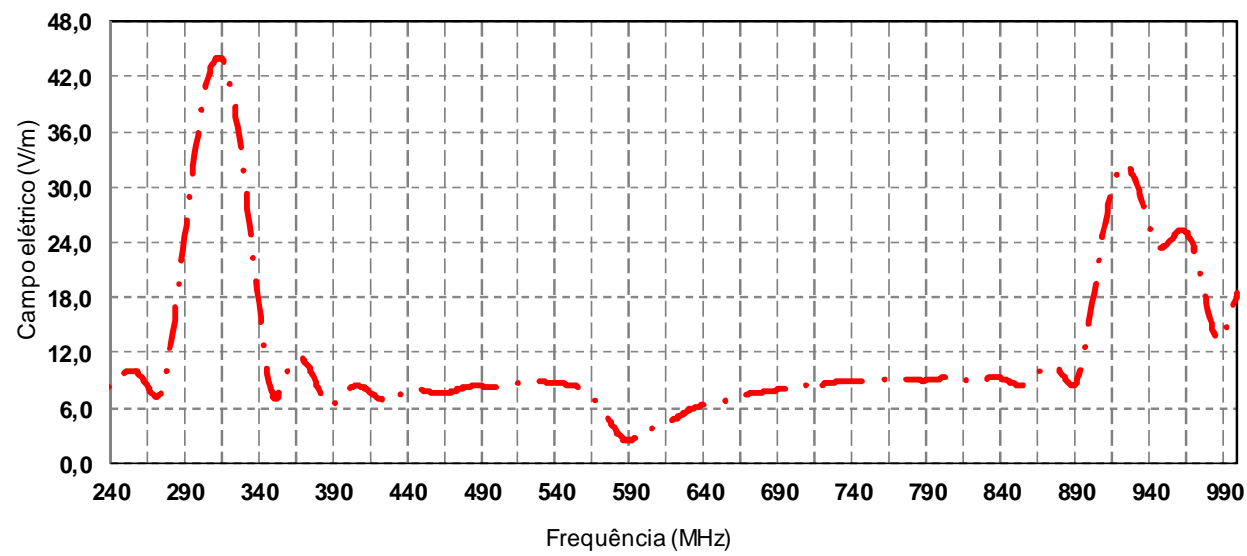

—- - Simulação campo elétrico sem a Blindagem-RG58 (50 W)

Fig. 11 - Valor do campo elétrico simulado com a abertura de $10 \mathrm{~cm}$ na blindagem do cabo RG-58 


\section{CONCLUSÃO}

A partir da implementação da metodologia proposta, concluiu-se que é possível determinar o fator de qualidade da blindagem de um cabo protótipo e compará-la com um cabo coaxial de referência. $\mathrm{O}$ fator de blindagem é medido em $\mathrm{dB}$ e blindagens eficientes apresentam uma atenuação da ordem de $100 \mathrm{~dB}$ ou mais [5]. Entretanto, deve-se controlar os níveis de ondas estacionárias do condutor que tiver impedância diferente de $50 \Omega$. Verificou-se, através das medições e simulações virtuais, que quanto maior o valor do fator de qualidade da blindagem melhor será o desempenho do cabo coaxial na ótica da suscetibilidade e emissões eletromagnéticas irradiadas.

\section{REFERÊNCIAS}

[1] PAUL, C.R, Introduction to Electromagnetic Compatibility, John Wiley \& Sons, Inc., New York, New York, 1992.

[2] Donald R.J, Michel Mardiguian, Electromagnetic Shielding, Interference Control Technologies, Inc. Volume 3, Gainesville, Virginia, 1988;

[3] R. De Leo, G. Cerri, V. Mariani Primiani, and R. Botticelli, A Simple But Effective Way for Cable Shielding Measurement, IEEE Transactions on Electromagnetic Compatibility, Vol. 41, August 1999.

[4] Mazhareddin Taghivand, Correlation between Shielding Effectiveness and Transfer Impedance of Shielded Cable, California Institute of Technology MC 136-93, 1200 E. California blvd., Pasadena, CA 91125.

[5] Institute of Electrical and Eletronics Engineers - IEEE, Standard Method for Measuring the Effectiveness of Electromagnetic Shielding Enclosures. IEEE, 2006;

[6] CST Microwave Studio cst Computer Simulation,Technology; AG. Disponível na Internet em <http://www.cst.com/Content/Applications/Markets/EMC EMI.aspx> Acessado em 02/05/2013; 